\title{
Poor sleep quality and its related risk factors among university students
}

\author{
Xiaohong Liu ${ }^{1 \#}$, Lin Lang ${ }^{2 \#, ~ R u i ~ W a n g ~}{ }^{3 \#}$, Wangyang Chen ${ }^{1}$, Xiaohua Ren ${ }^{1}$, Yi Lin ${ }^{1}$, Guanqing Chen ${ }^{1}$, \\ Chenchen Pan ${ }^{1}$, Wenying Zhao ${ }^{1}$, Tinghui $\mathrm{Li}^{1}$, Chunlei Han ${ }^{4}$, Lianping $\mathrm{He}^{1}$, Yuanlong $\mathrm{Gu}^{5}$ \\ ${ }^{1}$ School of Medicine, Taizhou University, Taizhou, China; ${ }^{2}$ Department of Surgery, Shanghai New Hongqiao International Medical Center, \\ Shanghai, China; ${ }^{3}$ Training Center for Comprehensive Quality and Ability of College Students, Anhui Institute of Information Technology, Wuhu, \\ China; ${ }^{4}$ School of public health and management, Binzhou medical university, Yantai, China; ${ }^{5}$ Department of Oncology, Taizhou Municipal Hospital, \\ Taizhou, China \\ Contributions: (I) Conception and design: L He, X Liu, Y Gu, C Han; (II) Administrative support: W Chen, X Ren; (III) Provision of study \\ materials or patients: R Wang, L He, L Lang; (IV) Collection and assembly of data: Y Lin, G Chen, C Pan, W Zhao, T Li; (V) Data analysis and \\ interpretation: L He, R Wang; (VI) Manuscript writing: All authors; (VII) Final approval of manuscript: All authors. \\ "These authors contributed equally to the work. \\ Correspondence to: Lianping He. No.1139 City Avenue, School of Medicine, Taizhou University, Taizhou 318000, China. Email: lianpinghe@tzc.edu.cn; \\ Yuanlong Gu. Department of Oncology, Taizhou Municipal Hospital, Taizhou 318000, China. Email: ylgu@tzc.edu.cn.
}

Background: Poor sleep quality is a major health problem worldwide. In universities, poor sleep quality
can effect student's ability to study and have a serious impact on their psychological and physical well-being.
The aim of this study was to explore the quality of sleep among university students and identify risk factors
associated with poor sleep quality.

Methods: A cross-sectional study was conducted and the Pittsburgh sleep quality index scale was used to measure sleep quality. The overall score of the PSQI ranges from 0 to 21 , with a score of 4 or less indicating good sleep quality, a score of 5-10 indicating fairly good sleep quality, 11-15 indicating fairly bad sleep quality, and a score of 16-21 indicating poor sleep quality.

Results: A total of 1,317 subjects were enrolled in the study. Most subjects were female (64.6\%) and rural based $(69.2 \%)$. Low intensity sports activity more than once per week was reported by $81.9 \%$ of subjects and $59.8 \%$ reported they participated in high-intensity sports more than once a week. In addition, $72.8 \%$ of subjects took a nap more than three times per week.

Conclusions: We found that physical activity and taking a nap may be important factors in improving sleep quality and preventing sleep disorders among university students.

Keywords: Exercise; risk factors; sleep; students; universities

Submitted Jan 31, 2021. Accepted for publication Apr 04, 2021.

doi: 10.21037/apm-21-472

View this article at: http://dx.doi.org/10.21037/apm-21-472

\section{Introduction}

Poor sleep quality is a major health problem worldwide (1-3). In universities, poor sleep quality can effect student's ability to study and have a serious impact on their psychological and physical well-being (4-8). The physical and mental health problems of university students caused by poor sleep quality have been the subject of several research studies $(9,10)$.
One study found that many university students sleep less than 6 hours every day, which is less than the $8-10$ hours recommended by the National Sleep Foundation (11). Approximately one-third of students suffer from insomnia, with about $40 \%$ reporting they wanted to sleep during the daytime $(11,12)$. Some studies have found that elite sport is associated with sleep quality (13). The Pittsburgh sleep quality index (PSQI) was adopted to measure sleep quality. 
The PSQI scale consists of seven factors: subjective sleep quality, sleep duration, sleep latency, sleep efficiency, sleep disturbances, use of sleep drugs, and daytime dysfunction. However, little is known on the relationship between different degrees of physical activity intensity and sleep quality among university students.

This objective of this study was to evaluate sleep quality and identify risk factors associated with poor sleep quality among university students. We results revealed that physical activity and nap may be important factors in improving sleep quality and preventing sleep disorders in this group. The results should attract public attention towards the promotion of sleep quality through physical activities and encourage more research on the relationship between nap and sleep quality.

We present the following article in accordance with the STROBE reporting checklist (available at http://dx.doi. org/10.21037/apm-21-472).

\section{Methods}

\section{Study design}

A cross-sectional study was conducted involving 1,317 subjects (466 males and 851 females), aged 16-24 years. All procedures performed in studies involving human participants were in accordance with the Declaration of Helsinki (as revised in 2013). Informed consent was obtained from all individual participants included in the study. The study was approved by institutional ethics board of Wannan Medical College. All subjects provided written informed consent to participate in the study. The study was approved by institutional ethics board of Wannan medical college.

\section{Measurement}

\section{General demographics}

Self-administered questionnaires consisting of general demographics (age, gender, parents' education, family income, nap habits, and physical activity) were used.

\section{Sleep quality}

The Pittsburgh sleep quality index (PSQI) was adopted to measure sleep quality. The PSQI scale consists of seven factors: subjective sleep quality, sleep duration, sleep latency, sleep efficiency, sleep disturbances, use of sleep drugs, and daytime dysfunction. The overall score of the PSQI ranges from 0 to 21 , with a score of 4 or less indicating good sleep quality, a score of 5-10 indicating fairly good sleep quality, 11-15 indicating fairly bad sleep quality, and a score of 16-21 indicating poor sleep quality. In this study, a total score of PSQI over 5 was defined as poor sleep quality.

\section{Physical activity}

Low-intensity sports were considered activities such as walking or tai-chi, which lasted 20 minutes or more, and high-intensity sports as those such as playing ball or running, lasting 20 minutes or more.

\section{Data analysis}

SPSS2 0 (Inc., Chicago, IL, USA) was used for data processing and statistical analysis. Independent sample $t$-test was used for continuous variables, while chi-square test was used for categorical variables such as gender, parents' education, family income, and physical activity intensity. $\mathrm{P}<0.05$ was defined as statistical significance.

\section{Results}

\section{General characteristic of the subjects included}

A total of 1317 subjects were enrolled. Most subjects were female (64.6\%) and rural (69.2\%) (Table 1). Almost 82\% of female subjects engaged in low-intensity sports more than once per week and $59.8 \%$ of rural subjects engaged in high-intensity sports more than once per week. In addition, $72.8 \%$ of all subjects took a nap more than three times per week. The family income was less than $¥ 10,000$ in $25.1 \%$ of respondents.

\section{Descriptive statistics of the components of the PSQI}

Table 2 shows descriptive statistics of the components of the PSQI, revealing $31.5 \%$ of students considered their subjective sleep quality to be very good, and $34.4 \%$ obtained a score of 0 for sleep latency. The distribution of the PSOI score was showed in Figure 1. The sleep duration factor shows that $74.7 \%$ of students slept more than 7 hours every day, and $87.5 \%$ obtained a sleep efficiency rating of more than $85 \%$ using the formula actual sleep time/actual time in bed. Only $0.7 \%$ of students scored 19 or more for sleep disorders, and $10.3 \%$ used sleep medicines. In the last category of daytime dysfunction scores, $7.5 \%$ of students scored more than 5 meaning they were unable to study 
Table 1 Subject characteristics

\begin{tabular}{|c|c|}
\hline Variable & $\begin{array}{l}\mathrm{N}(\%) \text { or mean } \pm \\
\text { standard deviation }\end{array}$ \\
\hline Age (years) & $19.5 \pm 1.3$ \\
\hline \multicolumn{2}{|l|}{ Gender, n (\%) } \\
\hline Male & $466(35.4)$ \\
\hline Female & $851(64.6)$ \\
\hline \multicolumn{2}{|l|}{ Father education, $\mathrm{n}(\%)$} \\
\hline Primary school and below & $245(18.6)$ \\
\hline Middle school & $904(68.6)$ \\
\hline College and above & $167(12.7)$ \\
\hline Missing data & $1(0.1)$ \\
\hline \multicolumn{2}{|l|}{ Mother education, n (\%) } \\
\hline Primary school and below & $586(44.5)$ \\
\hline Middle school & $628(47.7)$ \\
\hline College and above & $103(7.7)$ \\
\hline Missing data & $2(0.2)$ \\
\hline \multicolumn{2}{|l|}{ Location, n (\%) } \\
\hline Rural & $912(69.2)$ \\
\hline Urban & $404(30.7)$ \\
\hline Missing data & $1(0.1)$ \\
\hline \multicolumn{2}{|l|}{ Income (RMB), n (\%) } \\
\hline$<10,000$ & $331(25.1)$ \\
\hline $10,000-30,000$ & $430(32.6)$ \\
\hline $30,000-60,000$ & $395(30.0)$ \\
\hline$>60,000$ & $156(11.8)$ \\
\hline Missing data & $5(0.4)$ \\
\hline \multicolumn{2}{|l|}{ Low-intensity sports, n (\%) } \\
\hline Never & $239(18.1)$ \\
\hline 1 to 2 times per week & $722(54.8)$ \\
\hline 3 to 4 times per week & $271(20.6)$ \\
\hline More than 5 times per week & $85(6.5)$ \\
\hline \multicolumn{2}{|l|}{ High-intensity sports, n (\%) } \\
\hline Never & $529(40.2)$ \\
\hline 1 to 2 times per week & $609(46.2)$ \\
\hline 3 to 4 times per week & $127(9.6)$ \\
\hline More than 5 times per week & $52(3.9)$ \\
\hline
\end{tabular}

Table 1 (continued)
Table 1 (continued)

\begin{tabular}{lc}
\hline Variable & $\begin{array}{c}\mathrm{N}(\%) \text { or mean } \pm \\
\text { standard deviation }\end{array}$ \\
\hline Nap, $\mathrm{n}(\%)$ & $62(4.7)$ \\
Never & $83(6.3)$ \\
Almost no (< once a week) & $213(16.2)$ \\
Sometimes (1 to 2 times per week) & $416(31.6)$ \\
Often (3 to 4 times per week) & $542(41.2)$ \\
Everyday & $1(0.1)$ \\
Missing data & \\
Pittsburgh sleep quality index (PSQl) score, $\mathrm{n}(\%)$ \\
$<5$ & $904(68.6)$ \\
$\geq 5$ & $397(30.1)$ \\
Missing data & $16(1.2)$ \\
\hline
\end{tabular}

during the daytime (Table 3).

\section{Correlation of sleep quality with characteristics of subjects}

The correlation of sleep quality with characteristics of subjects was analyzed by chi-square test. The results showed that sleep quality was associated with high-intensity sports, low-intensity sports, and naps. No association was found between sleep quality and gender, parental education, location, or income (Table 3).

\section{Discussion}

The purpose of this study was to assess the risk factors affecting the sleep quality of university students in a cross-sectional study and to speculate the correlation between these factors and sleep quality. It was found that physical activities and nap were associated with sleep quality among university students. While most studies have paid attention to the relationship between competitive physical activity and sleep quality, this study found that both high-intensity and low-intensity physical activity may improve sleep quality. We speculate that physical activities to different degrees may consume university students' physical strength inducing fatigue reducing stress, both of which may improve sleep quality.

In our study, the rate of poor sleep quality among university students was $30.1 \%$, in comparison to $54.7 \%$ found in the study by Cheng et al. (14). Whilst this 
Table 2 Description statistics of the components of Pittsburgh sleep quality index (PSQI)

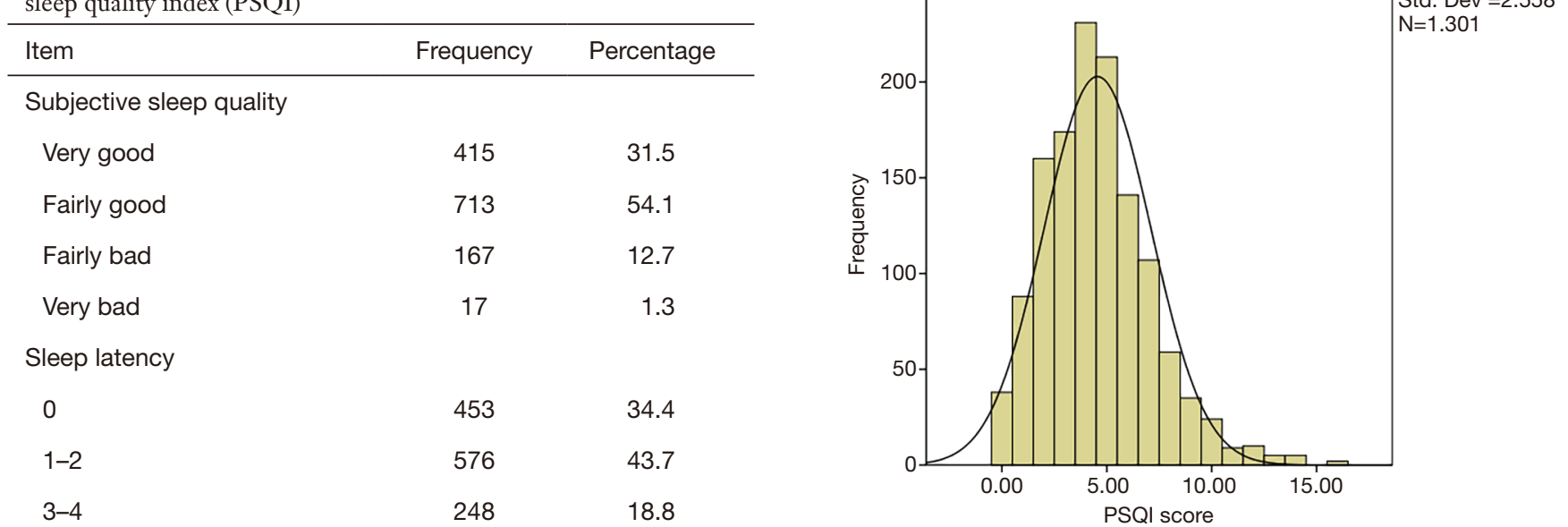

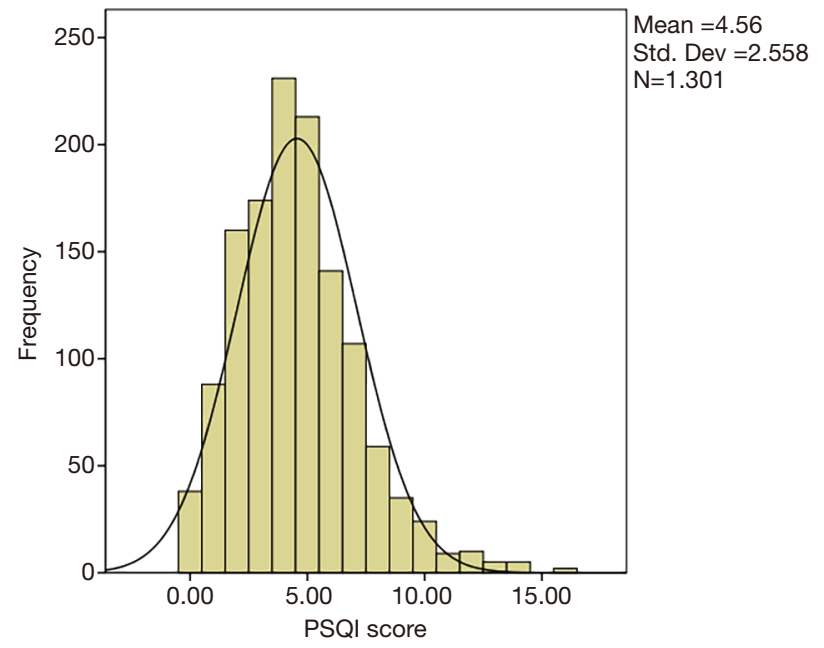

2.5

74.7

22.0

0.9

$<5$

Sleep efficiency $(\%)$

$>85$

1,152

87.5

75-84

121

$65-74$

$<65$

Sleep disturbances score

0

1-9

10-18

19-27

Use of sleep medication

Not during the past month

Less than once a week

Once or twice a week

Three or more times a week

Daytime dysfunction score

$$
0
$$$$
1-2
$$$$
\text { 3-4 }
$$$$
\text { 5-6 }
$$

Figure 1 Distribution of the PSQI score

discrepancy may be due to the use of different measurement methods between the two studies, it may also be due to our consideration of naps as a factor influencing sleep quality. While no previous studies have confirmed a relationship between nap and sleep quality, our results indicate that naps allow students to more successfully complete their daytime learning tasks and reduce lethargy, both of which could contribute to improving quality of sleep.

Finally, 43 students reported having used sleep medication, among which nine used sleep medicine more than three times per week, although the reasons for this were not explored. The possible reasons may be that there are too many curriculums need to do for university students.

A potential limitation of this study is that it was conducted in a single location and the results may not be transferable to other contexts. In addition, assessing the relationship between physical activity and sleep quality among university students should include other factors such as caffeine and tobacco intake, body mass index, and major area of study. Finally, as a cross-sectional study, the results only provide correlation and causal relationships cannot be inferred.

In summary, the results suggest that the incidence of poor sleep quality in university students is high, and more attention should be paid to the physical and mental health of this group. Promoting their participation in physical activities and developing effective work-rest programs is encouraged.

\section{Conclusions}

This study could pave the way for cohort studies on 
Table 3 The relationship between sleep quality and subject characteristics

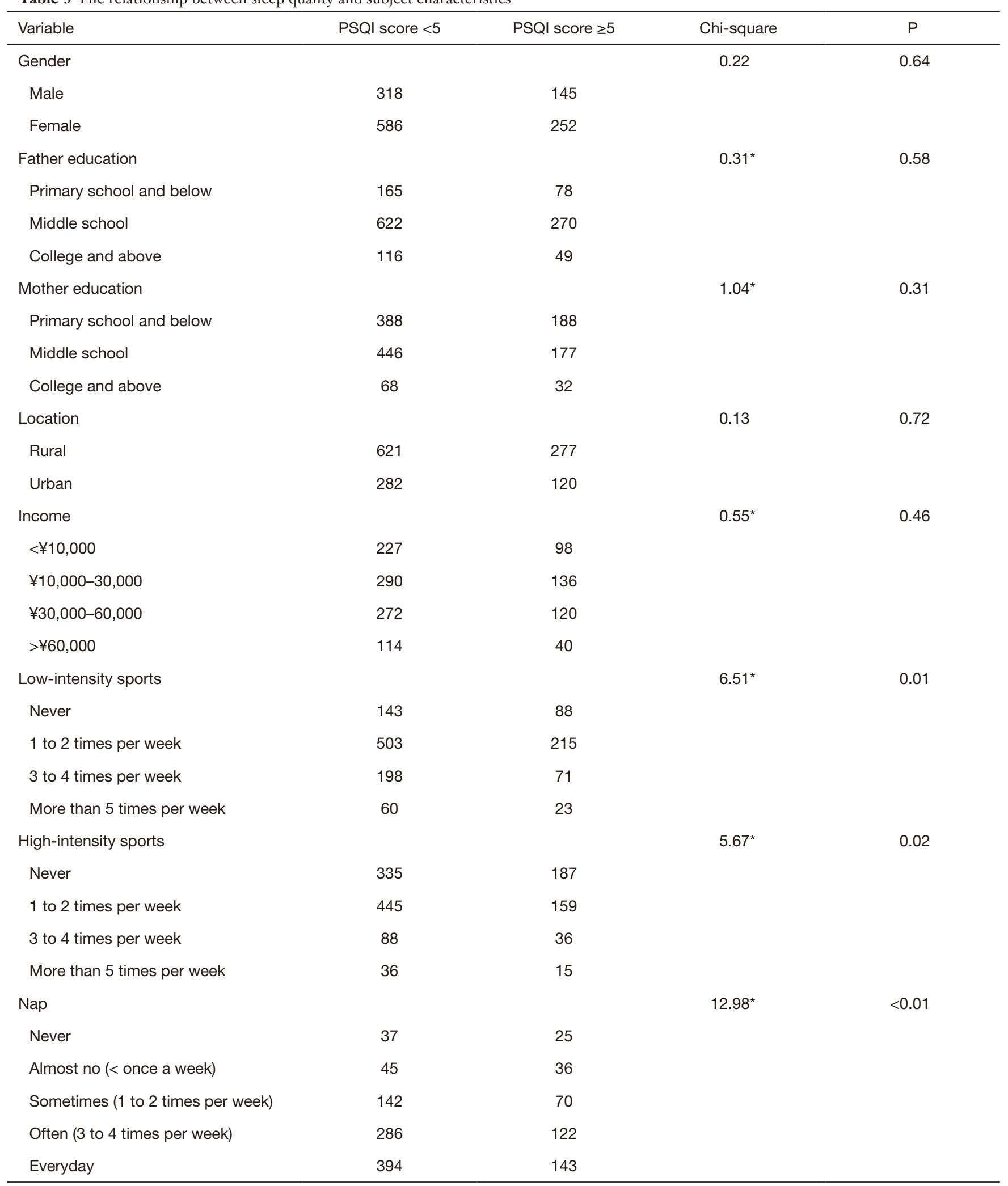

* represents linear-by-linear association. 
sleep quality and related factors in the population of university students. We found that physical activity and nap may be important factors in improving sleep quality and preventing sleep disorders in this group. The results should attract public attention towards the promotion of sleep quality through physical activities and encourage more research on the relationship between nap and sleep quality.

\section{Acknowledgments}

Funding: None.

\section{Footnote}

Reporting Checklist: The authors have completed the STROBE reporting checklist. Available at http://dx.doi. org/10.21037/apm-21-472

Data Sharing Statement: Available at http://dx.doi. org/10.21037/apm-21-472

Conflicts of Interest: All authors have completed the ICMJE uniform disclosure form (available at http://dx.doi. org/10.21037/apm-21-472). The authors have no conflicts of interest to declare.

Ethical Statement: The authors are accountable for all aspects of the work in ensuring that questions related to the accuracy or integrity of any part of the work are appropriately investigated and resolved. All procedures performed in studies involving human participants were in accordance with the Declaration of Helsinki (as revised in 2013). Informed consent was obtained from all individual participants included in the study. The study was approved by institutional ethics board of Wannan medical college.

Open Access Statement: This is an Open Access article distributed in accordance with the Creative Commons Attribution-NonCommercial-NoDerivs 4.0 International License (CC BY-NC-ND 4.0), which permits the noncommercial replication and distribution of the article with the strict proviso that no changes or edits are made and the original work is properly cited (including links to both the formal publication through the relevant DOI and the license). See: https://creativecommons.org/licenses/by-ncnd/4.0/.

\section{References}

1. Hui SK, Grandner MA. Associations between Poor Sleep Quality and Stages of Change of Multiple Health Behaviors among Participants of Employee Wellness Program. Prev Med Rep 2015;2:292-9.

2. Kawyannejad R, Mirzaei M, Valinejadi A, et al. General health of students of medical sciences and its relation to sleep quality, cell phone overuse, social networks and internet addiction. Biopsychosoc Med 2019;13:12.

3. Kataoka H, Miyatake N, Ichikawa H, et al. Relationship of locomotive syndrome with health-related quality of life among patients with obstructive sleep apnea syndrome. J Phys Ther Sci 2017;29:1129-1133.

4. Wang J, Chen Y, Jin Y, et al. Sleep quality is inversely related to body mass index among university students. Rev Assoc Med Bras (1992) 2019;65:845-50.

5. Alsaggaf MA, Wali SO, Merdad RA, et al. Sleep quantity, quality, and insomnia symptoms of medical students during clinical years. Relationship with stress and academic performance. Saudi Med J 2016;37:173-82.

6. Maheshwari G, Shaukat F. Impact of Poor Sleep Quality on the Academic Performance of Medical Students.

Cureus 2019;11:e4357.

7. Franquelo-Morales P, Sánchez-López M, NotarioPacheco B, et al. Association Between Health-Related Quality of Life, Obesity, Fitness, and Sleep Quality in Young Adults: The Cuenca Adult Study. Behav Sleep Med 2018;16:347-55.

8. Hernandez R, Vu TT, Kershaw KN, et al. The Association of Optimism with Sleep Duration and Quality: Findings from the Coronary Artery Risk and Development in Young Adults (CARDIA) Study. Behav Med 2020;46:100-11.

9. Iqbal S, Gupta S, Venkatarao E. Stress, anxiety and depression among medical undergraduate students and their socio-demographic correlates. Indian J Med Res 2015;141:354-57.

10. Iorga M, Dondas C, Zugun-Eloae C. Depressed as Freshmen, Stressed as Seniors: The Relationship between Depression, Perceived Stress and Academic Results among Medical Students. Behav Sci (Basel) 2018;8:70.

11. Hirshkowitz M, Whiton K, Albert SM, et al. National Sleep Foundation's sleep time duration recommendations: methodology and results summary. Sleep Health 2015;1:40-3.

12. Ramlee F, Sanborn AN, Tang NKY. What Sways People's Judgment of Sleep Quality? A Quantitative Choice- 
Making Study With Good and Poor Sleepers. Sleep 2017;40:zsx091.

13. Gupta L, Morgan K, Gilchrist S. Does Elite Sport Degrade Sleep Quality? A Systematic Review. Sports Med 2017;47:1317-33.

Cite this article as: Liu $\mathrm{X}$, Lang $\mathrm{L}$, Wang $\mathrm{R}$, Chen $\mathrm{W}$, Ren X, Lin Y, Chen G, Pan C, Zhao W, Li T, Han C, He L, Gu Y. Poor sleep quality and its related risk factors among university students. Ann Palliat Med 2021;10(4):4479-4485. doi: 10.21037/ apm-21-472
14. Cheng SH, Shih CC, Lee IH, et al. A study on the sleep quality of incoming university students. Psychiatry Res 2012;197:270-4.

(English Language Editor: B. Draper) 